\title{
A fast method for the retrieval of integrated longwave and shortwave top-of-atmosphere upwelling irradiances from MSG/SEVIRI (RRUMS)
}

\author{
M. Vázquez-Navarro ${ }^{1}$, B. Mayer $^{1,2}$, and H. Mannstein ${ }^{1,}$ \\ ${ }^{1}$ Deutsches Zentrum für Luft- und Raumfahrt (DLR), Institut für Physik der Atmosphäre, Oberpfaffenhofen, Germany \\ ${ }^{2}$ Ludwig-Maximilians-Universität (LMU), Meteorologisches Institut, München, Germany \\ deceased \\ Correspondence to: M. Vázquez-Navarro (margarita.vazquez@dlr.de)
}

Received: 22 June 2012 - Published in Atmos. Meas. Tech. Discuss.: 20 July 2012

Revised: 14 June 2013 - Accepted: 18 June 2013 - Published: 15 October 2013

\begin{abstract}
A new Rapid Retrieval of Upwelling irradiances from MSG/SEVIRI (RRUMS) is presented. It has been developed to observe the top-of-atmosphere irradiances of small scale and rapidly changing features that are not sufficiently resolved by specific Earth radiation budget sensors. Our retrieval takes advantage of the spatial and temporal resolution of MSG/SEVIRI and provides outgoing longwave and reflected shortwave radiation only by means of a combination of SEVIRI channels. The longwave retrieval is based on a simple linear combination of brightness temperatures from the SEVIRI infrared channels. The shortwave retrieval is based on a neural network that requires as input the visible and near-infrared SEVIRI channels. Both LW and SW algorithms have been validated by comparing their results with CERES and GERB irradiance observations. While being less accurate than their dedicated counterparts, the SEVIRI-based methods have two major advantages compared to CERES and GERB: their higher spatial resolution and the better temporal resolution. With our retrievals it is possible to observe the radiative effect of small-scale features such as cumulus clouds, cirrus clouds, or aircraft contrails. The spatial resolution of SEVIRI is $3 \mathrm{~km} \times 3 \mathrm{~km}$ in the sub-satellite point, remarkably better than that of CERES $(20 \mathrm{~km})$ or GERB $(45 \mathrm{~km})$. The temporal resolution is $15 \mathrm{~min}(5 \mathrm{~min}$ in the Rapid-Scan mode), the same as GERB, but significantly better than that of CERES which, being on board of a polar orbiting satellite, has a temporal resolution as low as 2 overpasses per day.
\end{abstract}

\section{Introduction}

Satellite observation of irradiances (fluxes) is essential for assessing the radiation budget of the Earth and its changes over time. Clouds exhibit a strong influence on the radiation budget by increasing the reflected shortwave irradiance by $47 \mathrm{~W} \mathrm{~m}^{-2}$ and reducing the outgoing longwave radiation by $30 \mathrm{~W} \mathrm{~m}^{-2}$, thus reducing the net energy input to the Earth-atmosphere system by about $17 \mathrm{~W} \mathrm{~m}^{-2}$ (Loeb et al., 2009). The cloud radiative effect shows high spatial variability, ranging from 0 in cloud-free areas to its largest values over deep convective systems, where up to $80 \%$ of the incoming solar radiation may be reflected by the cloud, and the outgoing longwave radiation may also be considerably reduced. In the study of the radiation budget, the high variability of clouds in space and time presents a big challenge. While averages, such as the ones mentioned above, may be derived from observations with low spatial and temporal resolution, the study of the radiative effect of individual cloud types requires the highest spatial and temporal resolution currently available. In this paper, we present a method, RRUMS, to derive the top of atmosphere irradiances based on SEVIRI, an instrument that presents the best combination of spatial and temporal resolution currently available over the MSGvisible part of the Earth.

Highly accurate Earth radiation budget (ERB) measurements have been typically made by polar orbiting satellites, the temporal resolution of which is not sufficient for the study of the aforementioned rapidly changing clouds processes. ERB data from polar orbiting satellites cannot provide proper 
temporal sampling, since they lack the multiple views necessary each day to resolve processes on short time scales. Diurnal variations in the radiation budget cannot be monitored with such platforms. In contrast, a geostationary platform allows much better temporal sampling. The GERB instrument (Harries et al., 2005), on board the geostationary satellite MSG, provides irradiance measurements with a high temporal resolution of $15 \mathrm{~min}$ since 2004, but its low spatial resolution is still insufficient to resolve smaller structures such as cumuli, cirrus, and aircraft contrails.

The aim of the retrieval presented here is to determine the radiative effect of small-scale atmospheric components (especially clouds) on the outgoing longwave and reflected shortwave radiation. For this purpose we utilise the MSG/SEVIRI instrument with a pixel size of $3 \mathrm{~km} \times 3 \mathrm{~km}$ at the sub-satellite point. It should be mentioned that the derived pixel-scale reflected shortwave or outgoing longwave irradiance is not an observable quantity because an instrument measuring at an arbitrary altitude would always average over larger areas. But it is the correct way to determine the effect of a small-scale feature on the radiation budget. The resolution and viewing geometry of course have to be considered when products from instruments on different satellites are compared, e.g Sun et al. (2006). To address these issues, Diner et al. (1999) introduced a terminology for the reflected solar radiation products derived from the MISR instrument, including "local", "restrictive", and "expansive" albedos. Our product comes closest to their "local" albedo, with the difference that we determine the reflected shortwave radiation separately for each satellite pixel (they average over several $275 \mathrm{~m}$ resolution pixels to obtain a $2.2 \mathrm{~km}$ product resolution). On the other hand, the MSG/SEVIRI pixel size is larger than their local resolution for which reason their terminology is not directly applicable. For comparison with other products, Diner et al. (1999) used a "reflecting level reference altitude" which is one possibility to consider the parallax error caused by different viewing angles. Also, threedimensional radiative transfer effects become more and more important when the resolution is increased. At the resolution of MSG/SEVIRI, however, the uncertainty due to cloud inhomogeneity effects should be close to its possible minimum which typically occurs at resolutions of a few kilometres, as several studies have shown (Davis et al., 1997; Varnai and Marshak, 2001; Zinner and Mayer, 2006): if the pixel size is larger (CERES, GERB) then the unresolved inhomogeneities cause increased uncertainties (plane-parallel bias) while independent column approximation errors become more important when the pixel size is smaller.

The work presented in this manuscript is motivated by the attempt to directly quantify the radiative impact of aircraft contrails and contrail cirrus. In a previous work we described an automatic contrail tracking algorithm (Vázquez-Navarro et al., 2010) which allows the tracking of aircraft contrails through a considerable part of their lifetime. The method proposed here allows - but is not limited to - the determination of the radiative effect of these man-made clouds with the final aim to quantify the total forcing by cirrus clouds generated or influenced by air traffic. For this purpose both an instrument and an algorithm are needed that provide irradiance measurements with very high temporal and spatial resolution. MSG/SEVIRI fulfils both resolution requirements. Moreover, the algorithm must be fast enough to process huge amounts of data.

Previously, there have been several attempts to derive broadband radiances from the SEVIRI narrowband channels. This reflects again the scientific necessity for the SEVIRI temporal and spatial resolution. EUMETSAT (2010) released a narrowband to broadband conversion for the Outgoing Longwave Radiation, as a result of a feasibility study. The irradiances are obtained via a regression scheme using the IR and WV SEVIRI radiances and the satellite viewing angle. The product is not operationally derived. SEVIRI has also been used to compute the broadband unfiltered radiances from the broadband filtered radiances measured by GERB (Clerbaux et al., 2008a, b). Different sets of second-order polynomial regressions based on the narrowband SEVIRI channels (thermal channels for LW and visible channels for $\mathrm{SW}$ ) were used. The unfiltered radiances estimated were later converted to irradiances using CERES Angular Dependency Models (ADMs). Additionally, GERB has a product with an increased resolution $(9 \mathrm{~km} \times 9 \mathrm{~km}$, corresponding to $3 \times 3$ SEVIRI pixels) that results from a combination of GERB and SEVIRI measurements. The underlying radiation model used both in Clerbaux and in the EUMETSAT regressions is SBDART (Ricchiazzi et al., 1998).

The algorithms we have developed are straightforward and fast methods to determine reflected solar radiation and outgoing longwave radiation using only MSG/SEVIRI data. The methods are based on a large set of forward simulations of the MSG/SEVIRI channels. The validations presented in this paper have been carried out by comparing the retrievals with the measurements of widely used instruments such as TERRA/CERES (for example, Loeb et al., 2005, 2007). The more recent instrument MSG/GERB (Harries et al., 2005) has also been used for the validation. The methods are shown to provide reasonably accurate results for our purpose. It can, of course, not compete with the absolute accuracy of a dedicated radiometer like CERES or GERB, but considering the improvement in the resolution, the retrieval is excellent for the determination of the instantaneous radiative effect of clouds.

\section{Methods}

In this section, we first briefly describe the satellite instruments used in this study: GERB and SEVIRI on Meteosat Second Generation, and CERES on Terra and Aqua. Then, a description of the model dataset (basis of the algorithms) 
Table 1. MSG/SEVIRI spectral channels. VIS = visible, $\mathrm{IR}=$ infrared, $\mathrm{WV}=$ water vapour.

\begin{tabular}{|c|c|c|c|c|c|}
\hline \multirow{2}{*}{$\frac{\#}{1}$} & \multirow{2}{*}{$\begin{array}{l}\text { Channel } \\
\text { VIS006 }\end{array}$} & \multirow{2}{*}{$\begin{array}{r}\begin{array}{r}\text { Nominal } \\
{[\mu \mathrm{m}]}\end{array} \\
0.64\end{array}$} & \multicolumn{3}{|c|}{$\begin{array}{l}\text { Wavelength range } \\
\qquad[\mu \mathrm{m}]\end{array}$} \\
\hline & & & 0.56 & - & 0.71 \\
\hline 2 & VIS008 & 0.81 & 0.74 & - & 0.88 \\
\hline 3 & IR_016 & 1.64 & 1.50 & - & 1.78 \\
\hline 4 & IR_039 & 3.92 & 3.48 & - & 4.36 \\
\hline 5 & WV_062 & 6.25 & 5.35 & - & 7.15 \\
\hline 6 & WV_073 & 7.35 & 6.85 & - & 7.85 \\
\hline 7 & IR_087 & 8.70 & 8.30 & - & 9.10 \\
\hline 8 & IR_097 & 9.66 & 9.38 & - & 9.94 \\
\hline 9 & IR_108 & 10.80 & 9.80 & - & 11.80 \\
\hline 10 & IR_120 & 12.00 & 11.00 & - & 13.00 \\
\hline 11 & IR_134 & 13.40 & 12.40 & - & 14.40 \\
\hline 12 & HRV & & 0.50 & - & 0.90 \\
\hline
\end{tabular}

follows. Finally, the retrieval algorithms for the outgoing longwave radiation and reflected shortwave radiation are explained.

\subsection{Satellites and Sensors}

\subsubsection{MSG}

Meteosat Second Generation (MSG) (Schmetz et al., 2002) is the operational geostationary weather satellite of the European meteorological satellite programme. The second generation of Meteosat consists of a series of four spin stabilised spacecraft that will operate consecutively. MSG carries two instruments: the Spinning Enhanced Visible and Infra-Red Imager (SEVIRI) and the Geostationary Earth Radiation Budget (GERB).

\section{GERB}

The GERB (Harries et al., 2005) instrument measures broadband solar and thermal radiances which are converted to outgoing longwave and reflected solar irradiances taking into account the cloud properties and surface type detected by SEVIRI to choose the correct angular distribution model (ADM) for each scene. In the shortwave range, some of CERES' ADMs are used (see the CERES description below). For longwave irradiance, a method based on thermal SEVIRI channels is used. It provides for the first time measurements of irradiances every $15 \mathrm{~min}$ and its nadir spatial resolution is $44.6 \mathrm{~km} \times 39.3 \mathrm{~km}$.

\section{SEVIRI}

The Spinning Enhanced Visible and Infra-Red Imager (SEVIRI) (Schmetz et al., 2002) combines the advantages of high temporal and high spatial resolution. MSG/SEVIRI, which became operational at the end of January 2004,

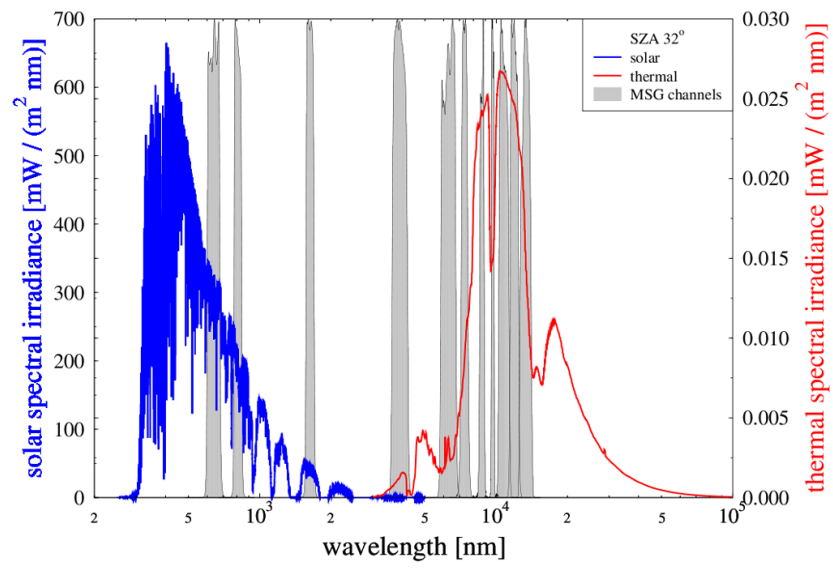

Fig. 1. MSG/SEVIRI spectral channels and an example spectrum of reflected solar and outgoing longwave irradiance.

provides data with a temporal resolution of $15 \mathrm{~min}$. The currently operational MSG (Meteosat-9) observes the "full disk" every 15 min while the back-up satellite Meteosat- 8 is operated in "Rapid-Scan mode" since 2008, which gives a temporal resolution of $5 \mathrm{~min}$ for the northern third of the visible hemisphere. SEVIRI comprises twelve spectral bands: four solar, seven thermal infrared, and a mixed solar/thermal channel at $3.9 \mu \mathrm{m}$ (see Table 1). The spectral coverage of the channels is shown in Fig. 1. The spatial resolution is $3 \mathrm{~km} \times 3 \mathrm{~km}$ at the sub-satellite point, except for the highresolution visible (HRV) channel which has a resolution of $1 \mathrm{~km} \times 1 \mathrm{~km}$ at the sub-satellite point.

\subsubsection{TERRA/CERES}

The Clouds and the Earth's Radiant Energy System (CERES) is a broadband scanning thermistor bolometer on board of several polar orbiting satellites (Wielicki et al., 1996), most recently on Terra and Aqua. CERES measures broadband solar and thermal radiances which are converted to irradiances using a sophisticated and well-characterised algorithm. The Angular Distribution Model (ADM) necessary for the conversion, uses scene analysis from the MODIS instrument aboard the same satellites (Loeb et al., 2005, 2007). The spatial resolution of CERES is $20 \mathrm{~km}$ at nadir. The CERES data are commonly used to study the radiation budget and have undergone a comprehensive validation.

\subsection{Forward model dataset}

To establish the relationship between MSG/SEVIRI channel radiances and broadband solar and thermal irradiances, a huge set of forward calculations of the eleven MSG/SEVIRI channels (excluding the high-resolution visible channel) plus the corresponding reflected solar and outgoing thermal irradiances was done with the radiative transfer package libRadtran (Mayer and Kylling, 2005). The thermal IR data have 
already been used by Krebs et al. (2007) in order to test the performance of a cirrus cloud detection algorithm. Reflectivities for the three solar channels and equivalent brightness temperatures for the seven thermal SEVIRI channels have been simulated for a wide and extensive range of atmospheric and surface conditions. Clerbaux et al. (2003) followed a very similar approach for the thermal IR.

LibRadtran offers a flexible interface to setup the atmospheric and surface conditions as well as a choice of different radiative transfer equation solvers. It has been successfully validated in several model intercomparison campaigns and by direct comparison with observations, e.g. Van Weele et al. (2000) and Mayer et al. (1997). For the simulation of radiances or brightness temperatures in this paper, we selected the DISORT 2.0 solver by Stamnes et al. (1988) with 16 streams because it allows accurate simulations of radiances. Molecular absorption was accounted for by the LOWTRAN atmospheric band model (Pierluissi and Peng, 1985) adopted from the SBDART radiative transfer code (Ricchiazzi and Gautier, 1998) which uses a three-term exponential sum fit with a resolution of $20 \mathrm{~cm}^{-1}$. Each SEVIRI channel is simulated with 15 spectral grid points, weighted with the filter function, and integrated over wavelength. Radiances were converted to equivalent brightness temperatures $T_{\mathrm{b}}$ using the following relationship:

$L=\frac{\int B_{\lambda}\left(T_{\mathrm{b}}\right) f(\lambda) d \lambda}{\int f(\lambda) d \lambda}$

where $f(\lambda)$ is the spectral response function, $B_{\lambda}\left(T_{\mathrm{b}}\right)$ is the Planck function, and $L$ is the spectrally integrated radiance (weighted with the spectral response function). Since this equation cannot be solved analytically, $T_{\mathrm{b}}$ is determined iteratively. Reflectivities $R$ were calculated from

$R=\frac{\pi \int L(\lambda) f(\lambda) d \lambda}{\int E_{0}(\lambda) f(\lambda) d \lambda \cos \theta_{0}}$

where $E_{0}(\lambda)$ is the extraterrestrial irradiance and $\theta_{0}$ is the solar zenith angle. As spectral response functions we used those of MSG1 provided by EUMETSAT.

For our dataset we used 10000 different randomly selected combinations of atmospheric conditions as input:

- profiles of pressure, temperature, water vapour, ozone concentration and other trace gases were taken from the TIGR-3 (Thermodynamic Initial Guess Retrieval) dataset (Chevallier et al., 1998);

- since we were specifically interested in ice clouds, each case was calculated with and without ice cloud; the ice cloud optical thickness was varied between 0 and 10 , the ice particle effective radius between 10 and $45 \mu \mathrm{m}$, with a bottom height between 6 and $10 \mathrm{~km}$ and a geometrical thickness of $0.5-2 \mathrm{~km}$; the habit was randomly selected from the six habits provided by Key et al. (2002) and Yang et al. (2005);
- $50 \%$ of the cases included a water cloud, with optical thickness between 5 and 50, droplet radius $5-15 \mu \mathrm{m}$, cloud bottom height $1-2 \mathrm{~km}$, and cloud geometrical thickness $0.5-2 \mathrm{~km}$;

- the surface skin temperature was calculated by adding a random $\pm 10 \mathrm{~K}$ to the temperature of the lowest level of the atmospheric profile and the surface emissivity in the thermal IR was assumed to be 1 in all cases. Some uncertainty might be introduced by this simplification, but emissivities are usually close to 1 in the infrared window region; also, the angular dependence is small: e.g. Sobrino and Cuecas (1999) found relative differences of only $3.3 \%, 2.0 \%$, and $0 \%$ between $\theta_{\mathrm{v}}=0$ and $\theta_{\mathrm{v}}=55^{\circ}$ for water, sand, and grass, respectively; for larger viewing zenith angles, the differences increase;

- for the calculation of the spectral BRDF (bi-directional reflectance distribution function) in the solar range, $50 \%$ of the cases were over ocean and $50 \%$ were over land. Over ocean, the BRDF was described by the well-established parameterization by Cox and Munk (1954) and Nakajima and Tanaka (1983). The wind speed was varied randomly between 1 and $15 \mathrm{~m} \mathrm{~s}^{-1}$. For the remaining $50 \%$ over land we used spectral land surface BRDFs for various surfaces where the spectral albedo was taken from randomly sampled MODIS pixels over woodland, grassland, snow, and desert and the angular distribution was described using the analytic formula by Rahman et al. (1993) with the parameters for the corresponding surface types;

- the cosine of the solar zenith angle was varied between 0.2 and 1.0, corresponding of a solar zenith angle between 0 and $78^{\circ}$.

For each atmospheric dataset, brightness temperatures were calculated for satellite zenith angles between 0 and $78^{\circ}$, in equidistant steps of 0.02 in the cosine of the satellite zenith angle and $10^{\circ}$ in the relative azimuth. A total of 7790000 data points were obtained in the solar spectral range (779 viewing angles for 10000 atmospheric conditions), and 410000 in the thermal spectral range (41 viewing angles for 10000 atmospheric conditions - the relative azimuth does not matter in the thermal). This test dataset covers a wide range of atmospheric and surface conditions and forms an ideal basis for determining the relationship between satellite observations and TOA solar and thermal irradiances.

\subsection{Retrieval algorithms}

RRUMS uses 10 SEVIRI channels (excluding the HRV and the mixed solar-thermal $3.9 \mu \mathrm{m}$ channel) in order to determine solar and thermal irradiance at top of atmosphere. In contrast to the above mentioned retrievals by CERES and GERB it does not explicitly use information about the scene 
provided by additional sensors. However, some information on the scene type is of course inherently delivered by the spectral information of the SEVIRI channels and enters into the retrieval. The rationale for not using a scene classification was that SEVIRI itself includes enough information about the scene which should be implicitly considered by our algorithm. For the thermal irradiance a simple linear combination of the seven thermal-infrared SEVIRI channels proved to be accurate enough (see Validation below). We actually did some scene classification by distinguishing between cases with and without ice clouds. For the solar irradiance we tried both a linear combination and a neural network. Both approaches are based on the three shortwave channels (VIS006, VIS008 and IR_016). The neural network turned out to be more convenient than the linear approach since for the latter we would have required, in addition to the cirrus discrimination, a cloud classification to separate between cases with and without low clouds. The neural network implicitly "knows" about the cloud type from the SEVIRI channels. "knows" is probably too strong, but one could say that the neural network takes best advantage of the available information and applies the optimum ADM.

Below, we describe the outgoing longwave radiation (OLR) retrieval algorithm and both reflected solar radiation (RSR) approaches, followed by a discussion on the most suitable RSR method.

\subsubsection{Outgoing longwave radiation, OLR}

According to Stefan-Boltzmann's law, the irradiance emitted by a blackbody is proportional to the fourth power of its temperature. For the fit of the thermal irradiance we therefore decided on the following form:

$F_{\mathrm{LW}}=\sigma\left(a_{0}\left(\theta_{\mathrm{v}}\right)+\sum_{i=5}^{11} a_{i}\left(\theta_{\mathrm{v}}\right) \cdot T_{i}\right)^{4}$

where the sum is over the seven thermal channels of MSG/SEVIRI (see Table 1) and $T_{i}$ are the respective brightness temperatures.

The coefficients $a_{i}\left(\theta_{\mathrm{v}}\right)$ were determined by minimising the mean square difference between fitted and actual irradiances for the whole forward model dataset. The parameters have been calculated as function of the satellite (or viewing) zenith angle $\theta_{\mathrm{v}}$ in equidistant steps of 0.02 in the cosine of the satellite zenith angle. Since we were particularly interested in cirrus clouds, different coefficients were used for cirrus-free and cirrus-covered scenes. MeCiDA (Meteosat Cirrus Detection Algorithm) by Krebs et al. (2007) and Ewald et al. (2013) is used for the discrimination. The coefficients as a function of satellite zenith angle for both the cases with and without cirrus are provided as supplementary material. There is a strong dependence on satellite zenith angle, the coefficients may be the positive or negative, and there is a strong difference between the cases with and without cirrus. We also found that these coefficients are very robust: we found nearly identical sets of coefficients when we randomly selected only one tenth of the forward model dataset. Without even trying to interpret the physical meaning of these parameters, one could infer from the positive and negative signs that the linear fit takes advantage of channel differences which are often exploited for cloud remote sensing, see e.g. Krebs et al. (2007).

Figure 2 illustrates the agreement between the "true" OLR and the fit according to Eq. (3). While the agreement for cirrus-free cases is generally good (upper plot; RMS difference $1.7 \mathrm{~W} \mathrm{~m}^{-2}$ ), the deviation is larger for cases with cirrus clouds (lower plot, RMS difference $2.5 \mathrm{~W} \mathrm{~m}^{-2}$ ). To further investigate this behaviour we separated the dataset into 8 ranges of satellite viewing angles $\mu_{\mathrm{v}}=\cos \theta_{\mathrm{v}}$, from 0.2 $0.3,0.3-0.4, \ldots, 0.9-1.0$. Figure 3 clearly shows that the agreement is best for viewing angles around $50^{\circ}\left(\mu_{\mathrm{v}}=0.6\right.$ ... 0.7; RMS difference $1.3 \mathrm{~W} \mathrm{~m}^{-} 2$ ) while the differences increase by more than a factor 3 towards larger viewing angles $\left(\mu_{\mathrm{v}}=0.2 \ldots 0.3\right.$ : RMS difference $\left.4.6 \mathrm{~W} \mathrm{~m}^{-2}\right)$. This implies that best results are to be expected for areas such as Central Europe where the viewing angle of Meteosat is between $50^{\circ}$ and $60^{\circ}$.

To explain this behaviour, we looked at the variability of the integrated thermal radiance for a given OLR as a function of viewing angle. This basically illustrates the variability of the angular distribution model (see e.g. Loeb et al., 2003) for a given angle. Please note that, in contrast to other procedures to derive OLR from narrowband radiances, we do not distinguish between the narrowband-to-broadband conversion (which converts from narrowband radiances to integrated thermal radiances) and the angular distribution model which converts from radiance to irradiance. Rather, both steps are combined in Eq. (3). If the variability of the radiances is large for a given OLR, then we expect a large uncertainty in the derived irradiances. Figure 4 shows the ADM, that is, the ratio of radiance $L$ and OLR $E$ multiplied by $\pi$ :

$\mathrm{ADM}=\frac{\pi L\left(\theta_{\mathrm{v}}\right)}{E}$

For a perfectly isotropic thermal irradiance we would get a constant value of 1 . In contrast, the graph shows a decrease of radiance with increasing viewing angle, $\theta_{\mathrm{v}}$, which is to be expected for an atmosphere where the temperature decreases with height: with increasing viewing angle the slant optical thickness along the line-of-sight increases; this causes a shift of the effective thermal emission towards higher altitudes and thus, lower temperature. More important for our application, however, is the fact that the variability of the radiance for the cases with cirrus clouds is considerably larger than for the cases without: the radiance above a thin cirrus can be seen as a mixture of the radiance emitted by the surface and atmosphere or lower clouds and the radiance emitted by the cirrus cloud: the larger the slant optical thickness, the lower the 

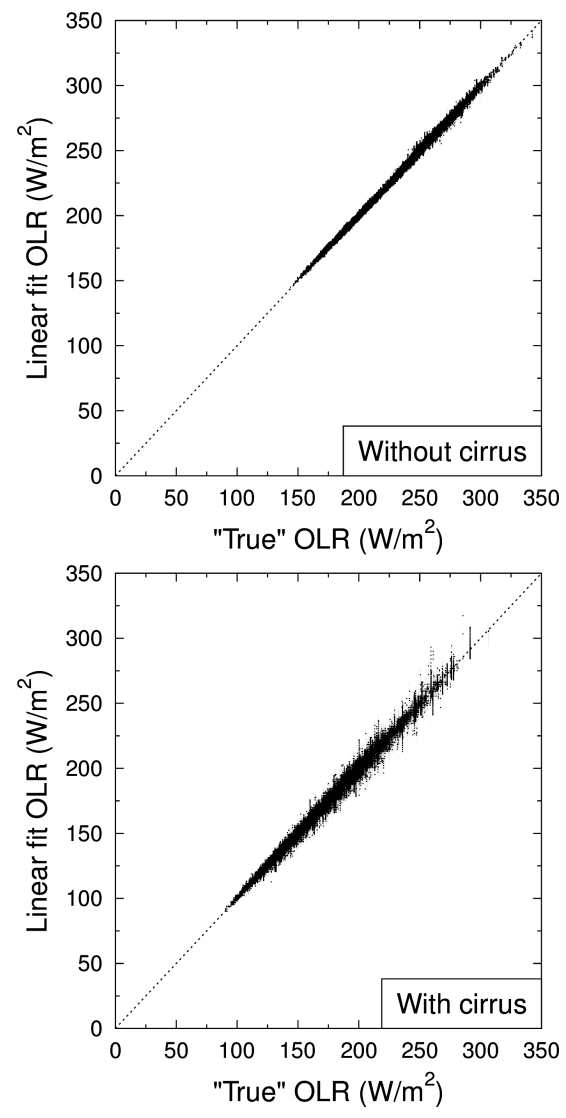

Fig. 2. Comparison between "true OLR" and the linear fit for cirrusfree cases (top) and cases with cirrus clouds (bottom).

emitting temperature, for this reason one can expect highly non-isotropic radiance for optically thin clouds. This is finally illustrated with Fig. 5 which shows the ratio of the radiances at $\theta_{\mathrm{v}}=0\left(\mu_{\mathrm{v}}=1\right)$ and $\theta_{\mathrm{v}}=78^{\circ}\left(\mu_{\mathrm{v}}=0.2\right)$ as a measure of anisotropy; for perfectly isotropic radiance this number would be 1 . In reality we find the largest deviation from 1 for a visible optical thickness of about 1 . The largest deviations occur obviously for semi-transparent clouds, as expected.

The figure suggests that the irradiance retrieval could be improved by including more information about the atmosphere, in particular cloud type, cloud top-temperature, and cloud optical thickness. Scene type classification provided by independent instruments is used, e.g. in the CERES retrieval described by Loeb et al. (2000, 2003): in the longwave, scenes are classified into clear, broken, and overcast. Additionally, for the non-overcast cases, the surface type (ocean, land, desert) is taken into account. In our OLR retrieval we separate only into scenes with and without cirrus clouds. Separating the low clouds did not bring any improvement; neither did the separation into surface types, since in our forward model all surfaces were considered isotropic emitters of thermal radiation (and the anisotropy is small anyway, as dis-
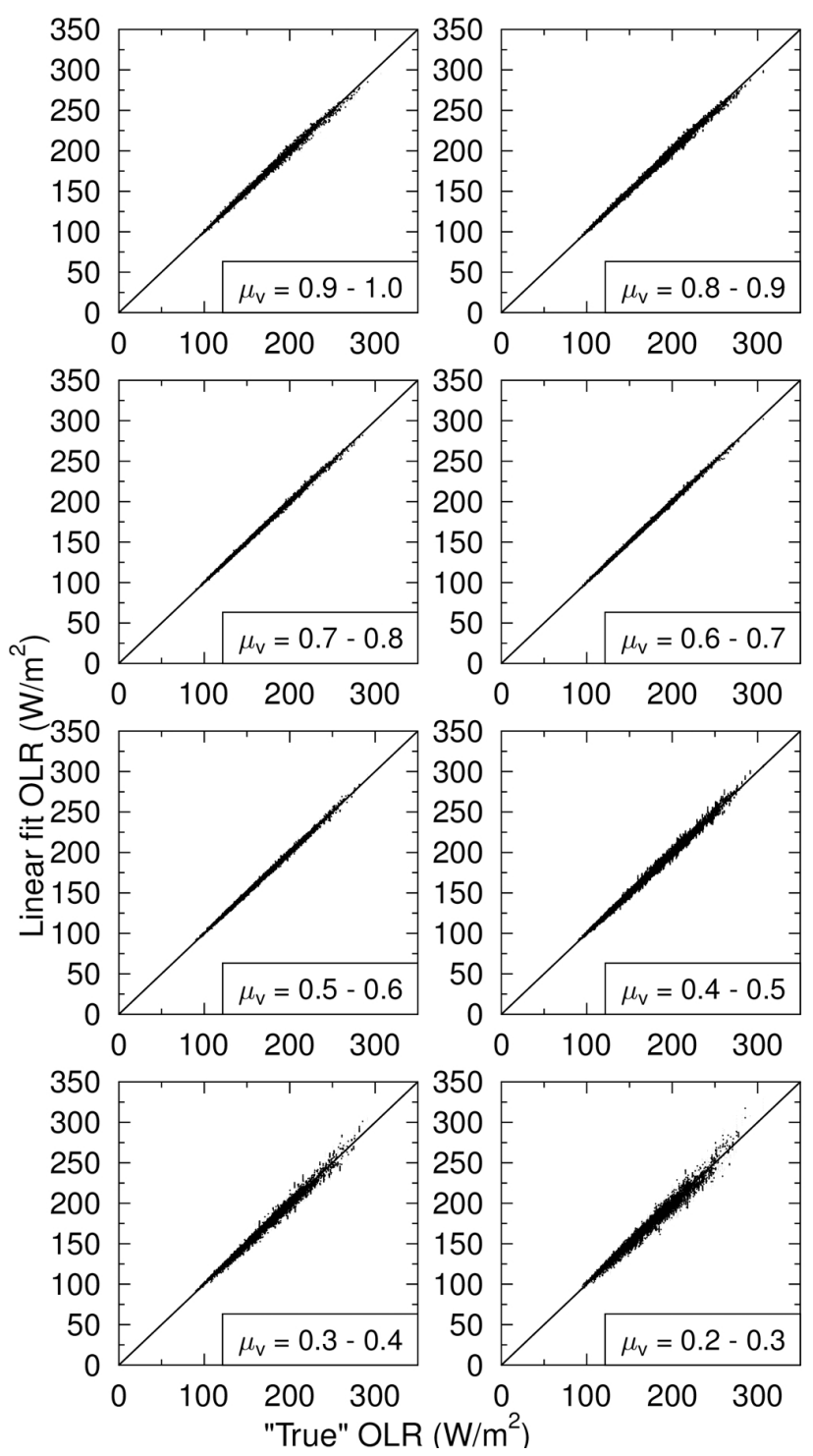

Fig. 3. Same as Fig. 2, but for cases with cirrus clouds and split into several viewing angle ranges.

cussed above). According to Fig. 5, the uncertainty could be reduced slightly if fit parameters were calculated as function of the cirrus optical thickness. However, we did not consider that in our analysis because (a) an optical thickness retrieval is computationally very expensive compared to the application of Eq. (3) and the cirrus detection, and (b) the retrieved optical thickness is uncertain anyway for semi-transparent cirrus clouds.

An example of the RRUMS OLR algorithm in comparison with the current available instruments (CERES and GERB) can be seen in Fig. 6. For the sake of easing comparisons, all satellite scenes depicting examples of the OLR and RSR applications in this paper correspond to the area shown in false colour in Fig. 7. It can be seen that while the irra- 

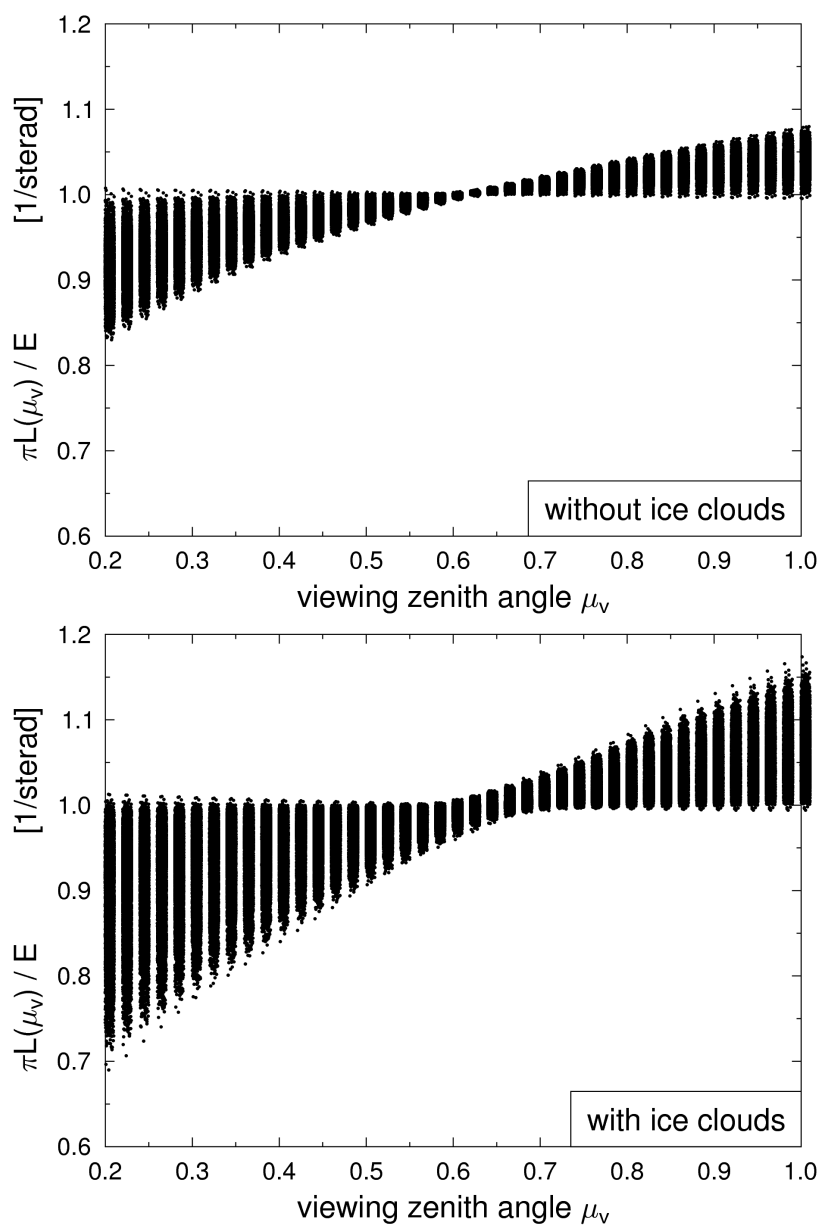

Fig. 4. The ADM (see Eq. 4) as a function of the cosine of the viewing zenith angle $\mu_{\mathrm{v}}=\cos \theta_{\mathrm{v}}$ for cases without (top) and with (bottom) cirrus.

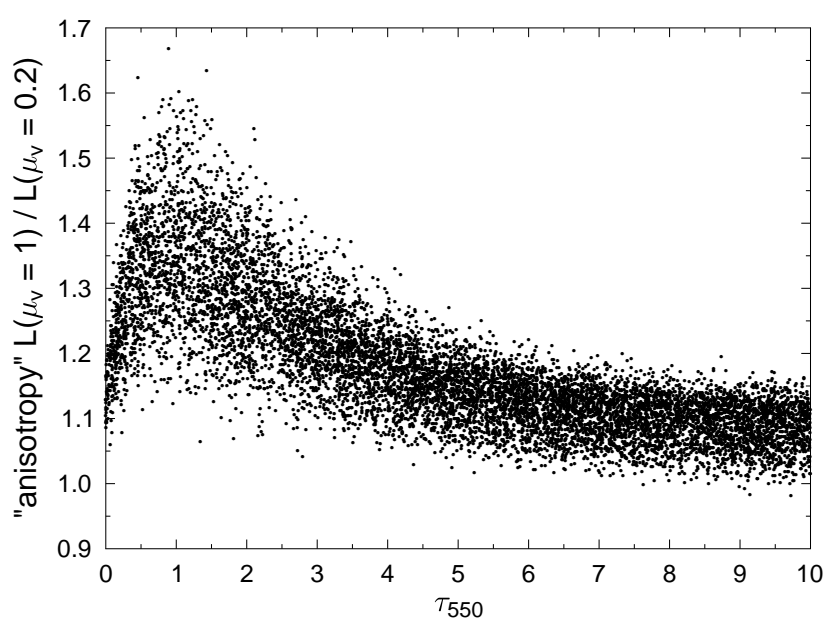

Fig. 5. The "anisotropy", defined as the ratio of nadir radiance and radiance at $78^{\circ}$ viewing angle, as function of the visible optical thickness.
Table 2. Comparison between SEVIRI-based RRUMS retrieval, EUMETSAT retrieval and corresponding CERES and GERB measurements for the scene depicted in Fig. 6. Bias and standard deviation in $\mathrm{W} \mathrm{m}^{-2}$.

\begin{tabular}{llrr}
\hline & & GERB & CERES \\
\hline \multirow{2}{*}{ RRUMS } & Std. dev. & 16.297 & 9.817 \\
& Bias & 2.499 & 1.260 \\
EUMETSAT & Std. dev. & 16.632 & 9.883 \\
& Bias & -1.527 & -2.832 \\
\hline
\end{tabular}

diance values remain virtually the same, there is a strong improvement in the spatial resolution and also in the coverage, when compared to CERES. A further comparison with the (non-operational) EUMETSAT tables for deriving OLR from the radiances (EUMETSAT, 2010) has been carried out and is also shown. It can be clearly seen that a very high agreement between both methods (RRUMS and EUMETSAT) can be clearly observed, so only one scene is shown here, exemplarily. The statistical analysis for the depicted scene is summarised in Table 2. It can be seen that, in general, the similarity is excellent. However, RRUMS has the advantage that it only requires a cirrus mask, whereas the EUMETSAT approach requires a three-level classification: semi-transparent clouds, opaque clouds and clear sky.

\subsubsection{Reflected solar radiation, RSR}

To retrieve the outgoing irradiance in the shortwave part of the spectrum, the reflected solar radiation, we followed two approaches: a linear fit based on solar radiances similar to that used for the OLR, and a neural network.

In the linear fit, we assumed the reflectivity can be written as a weighted sum over the reflectivities in the three shortwave channels, VIS006, VIS008, and IR_016:

$$
\begin{aligned}
F_{\mathrm{SW}} & =b_{0}\left(\theta_{\mathrm{v}}, \theta_{\mathrm{s}}, \Delta \phi, \mathrm{SUR}\right) \\
& +\sum_{i=1}^{3} b_{i}\left(\theta_{\mathrm{v}}, \theta_{\mathrm{s}}, \Delta \phi, \mathrm{SUR}\right) \cdot R_{i}
\end{aligned}
$$

Similar to the OLR, where we used brightness temperatures instead of radiances, we decided to use reflectivities to achieve independence of the specific instrument channel response. This allows us to apply the same algorithm to all four SEVIRI instruments of the MSG series. The solar fit coefficients $b_{i}$ had to be determined separately for cirrus and cirrus-free cases, for all 41 viewing angles $\theta_{\mathrm{v}}$, for the 19 relative azimuth angles $\Delta \phi$, and for solar zenith angle $\theta_{\mathrm{s}}$ intervals of 0.05 in the cosine of the solar zenith angle. SUR stands for surface type where we distinguished between land and water because the BRDF of land and water surfaces are fundamentally different.

During the validation with CERES and GERB, the linear fit showed less satisfactory results than the neural network. 


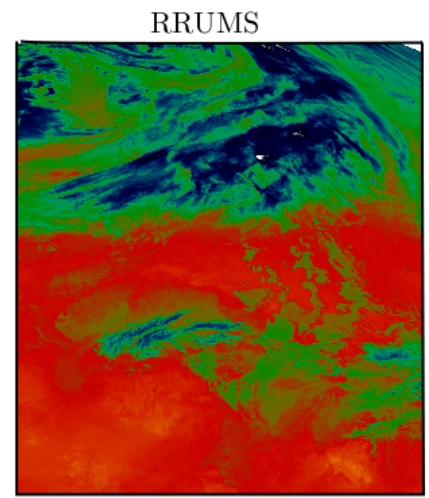

GERB

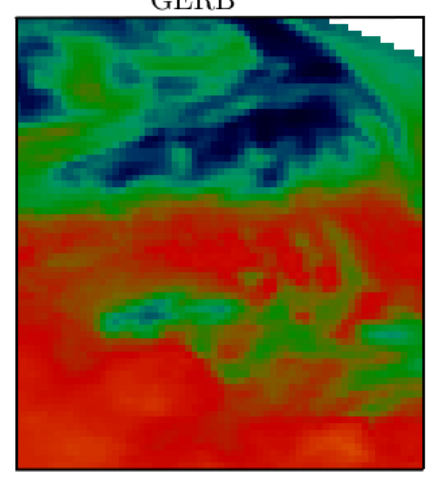

OLR $\left(W / m^{2}\right)$

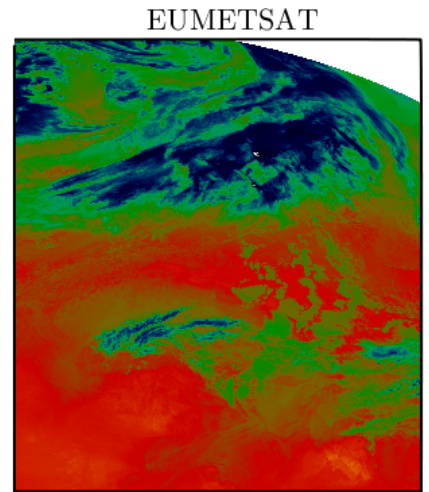

CERES

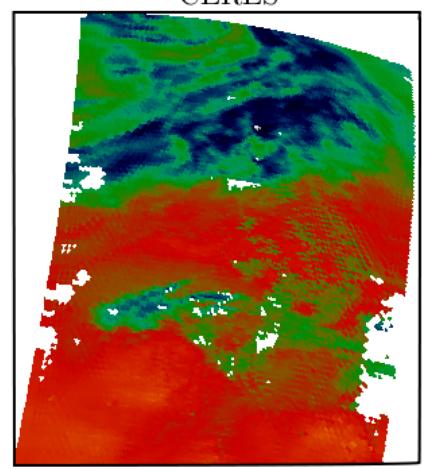

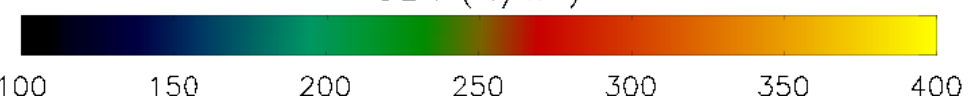

Fig. 6. Comparison between the SEVIRI-based methods to derive OLR (RRUMS and the EUMETSAT algorithm) and the two current irradiance measurement instruments (CERES and GERB). The blank areas are missing data due to the instrument characteristics. Same scene as Fig. 7. Date: 1 January 2007, 10:00 UTC

Therefore, although we carried out both approaches, we shall only describe the neural network here.

The motivation for using a neural network is that an extra scene classification is not required. The scene classification would need to rely on the same data anyway (SEVIRI), since there is no higher resolution sensor available on MSG, and the hope is that the neural network should inherently do the scene classification. In the CERES retrieval by Loeb et al. (2005) the scene classification is based on higher-resolution MODIS data from the same satellite platform. The GERB retrieval uses SEVIRI data for the cloud classification (Harries et al., 2005).

The neural network was trained with the reflectivities VIS006, VIS008, and IR_016 (same as for the linear fit), the viewing zenith angle $\theta_{\mathrm{v}}$, the solar zenith angle $\theta_{\mathrm{s}}$, the relative azimuth $\Delta \phi$, the land/water information, and of course the reflected shortwave irradiance as output. The artificial neural network was set up with only one hidden layer of 200 nodes, and the sigmoid function was applied to both the weighted sum of input and hidden layer nodes. The input dataset is presented to the backward error propagation training several times in random order. The data has been split into a training and a validation dataset. We trained a network with 200 nodes resulting in 2002 weights using 9172000 data vectors obtained from model calculations and used the same amount of data for validation. In order to force the network to reach a value of zero at night we had to add both in training and validation 1382000 data vectors linearly interpolated between 0 and the model results for large solar zenith angles, as the model calculations stopped at $78^{\circ}$ (cosine of zenith angle 0.2). The performance of the trained network is shown in Fig. 8. It must be noted that, unlike for OLR, a separation into cases with and without cirrus clouds is not necessary for the neural network retrieval.

A systematic deviation is observed for the largest irradiances which are underestimated by the neural network. The largest deviations, however, occur at irradiances of approximately $80 \mathrm{~W} \mathrm{~m}^{-2}$. The peak at small values of the RSR corresponds to reflection from cloud-free ocean: the reflectivity of the ocean increases with increasing solar zenith angle, which nearly compensates the decrease of the incident solar irradiance with the cosine of the solar zenith angle. For that reason, in cloud-free conditions the reflected solar irradiance is nearly independent of solar zenith angle, while for 


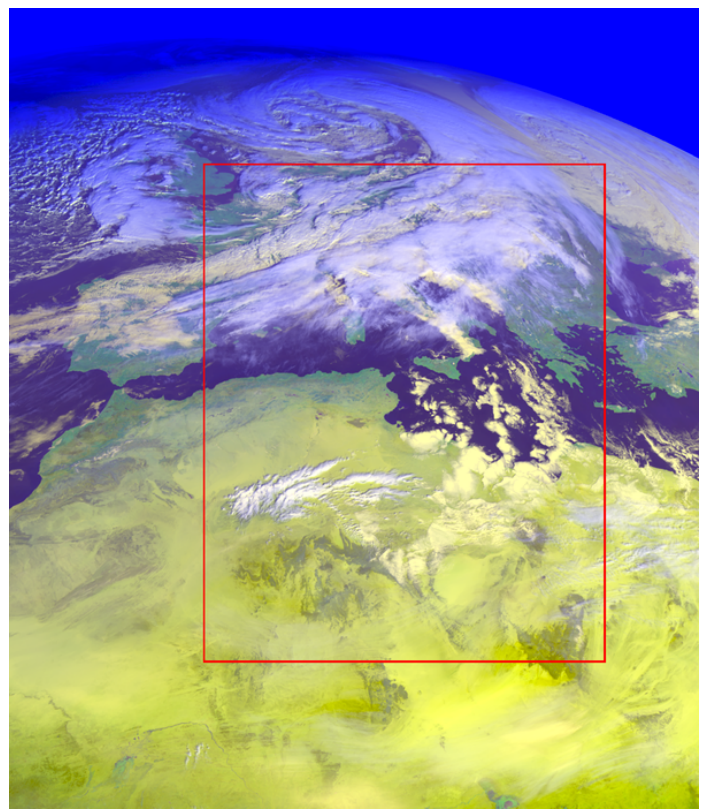

Fig. 7. RGB false colour composite of the area (in red) from SEVIRI corresponding to the comparisons in Figs. 6, 9, 10 and F11. Date and time: 1 January 2007, 10:00 UTC.

cloudy conditions we get the expected decrease of the reflected irradiance with increasing solar zenith angle. It has been observed that this neural network sometimes fails detecting thin clouds over the ocean. In those cases, the cloudless sky irradiance is wrongly assigned to the cloudy case and vice versa. Over land, and in presence of low water clouds, the neural network is able to represent the modelled data without a substantial bias. Bias and standard deviation determined by the validation dataset are 9.1 and $33.4 \mathrm{~W} \mathrm{~m}^{-2}$ ( 9.3 and $32.8 \mathrm{~W} \mathrm{~m}^{-2}$ for the training set).

A comparison of the RSR algorithm with the corresponding GERB and CERES measurements can be seen in Fig. 9. It is the same area over Europe, Mediterranean Sea, and Africa, including low and high clouds, water, land, desert and mountains/snow already shown for OLR (Fig. 6) and in the RGBfalse colour composite in Fig. 7. The different footprints are due to either the satellite/instrument footprint, the boundaries of the calculation method applied, or both. It can be seen that the RSR algorithm denotes an improvement in spatial resolution while providing similar irradiances.

More quantitatively, Fig. 10 directly compares the retrieval with the CERES and GERB observations. The neural network shows a good agreement with both GERB and CERES irradiance measurements.

\section{Validation of RSR and OLR retrieval algorithms}

Since the newly developed fast RRUMS methods are based on radiative transfer simulations only, they need to be vali-

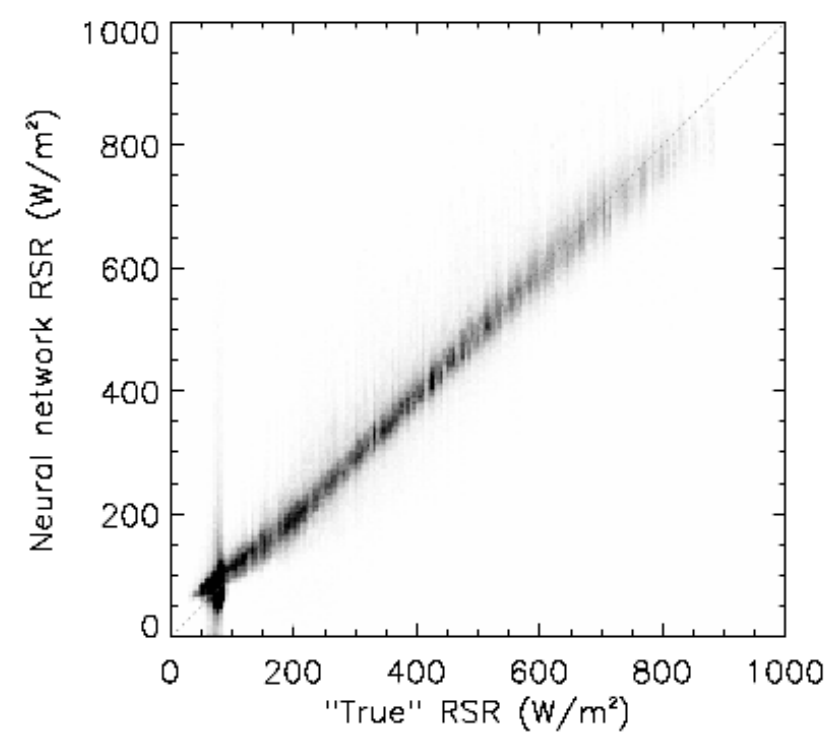

Fig. 8. Comparison between "true" SW irradiance and RRUMS, the neural network retrieval.

dated by comparison with independent observations. In the following we show a comparison with results derived from the CERES and GERB instruments. We have chosen CERES because it is the reference instrument for radiation budget measurements, and GERB because it is the broadband radiometer on board of MSG, so it shares SEVIRI's viewing geometry.

The use of three instruments with three different spatial resolutions required careful handling and processing of the data to avoid loss of information. SEVIRI-derived RRUMS data have a substantially better resolution than CERES or GERB data. For the comparison with CERES, data were first mapped onto a geostationary projection with the same nadir point as SEVIRI. This step was obviously not necessary for GERB. Second, SEVIRI data were mapped onto the lower resolution grid by averaging the SEVIRI data over the corresponding CERES or GERB pixels.

The results of the comparison with CERES are summarised in Table 3. For each date and wavelength range, CERES data have been plotted against RRUMS data, and have been fitted to a straight line $y=m x$, with the measured CERES irradiance as $x$, RRUMS-derived irradiance as $y$, slope $m$, and correlation coefficient $r$. The total agreement would correspond to slope 1 and correlation coefficient 1. The SW analysis was of course only done for daytime. The missing data in the table correspond to nighttime scenes, where only LW was evaluated since SW is zero anyway. It can be seen that, in general, the agreement between the CERES observations and the SEVIRI-based RRUMS is very good, in particular for OLR.

The discrepancies from the total agreement are more relevant in the SW case. Possible causes were analysed 

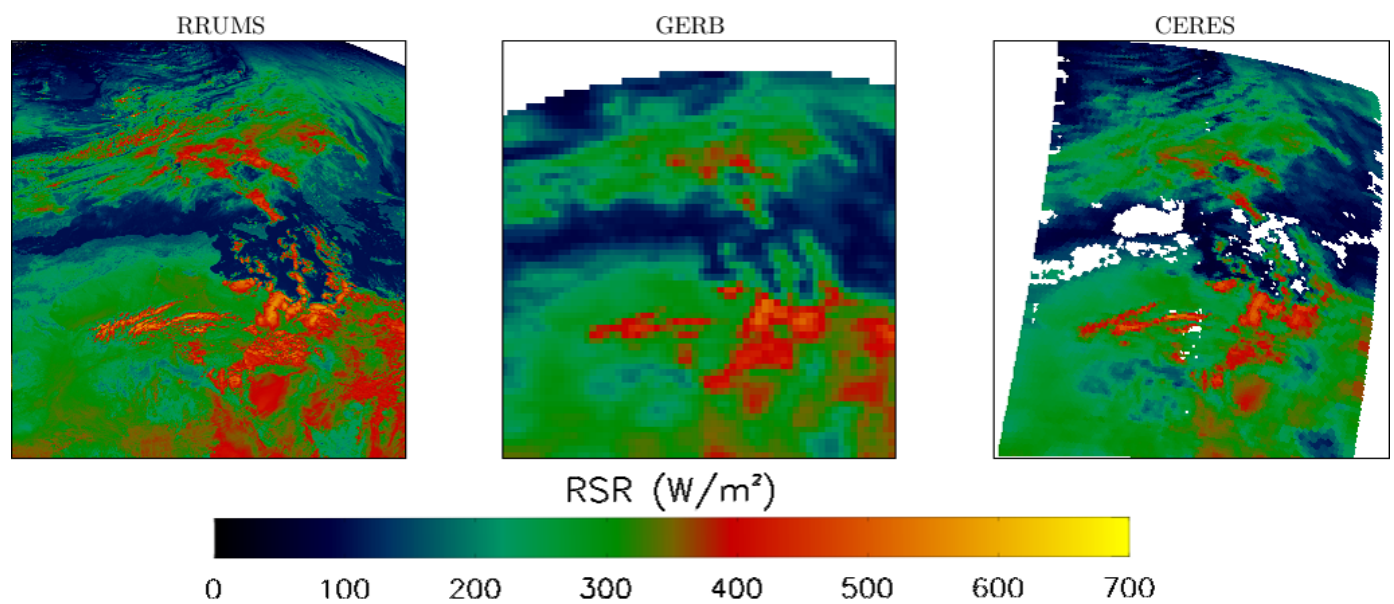

Fig. 9. Comparison between the SW measured irradiances (GERB and CERES) and the RRUMS retrieval. The white areas in all plots are due either to the instrument characteristics or to the method constraints. The corresponding RGB false colour composite can be seen in Fig. 7. Date: 1 January 2007, 10:00 UTC

Table 3. Comparison between SEVIRI-based RRUMS retrieval and CERES measurements. Bias and standard deviation in $\mathrm{W} \mathrm{m}^{-2}$.

\begin{tabular}{|c|c|c|c|c|c|c|c|c|c|c|}
\hline \multirow{2}{*}{$\begin{array}{l}\text { Date } \\
2004\end{array}$} & \multicolumn{2}{|c|}{ Overpass time (UTC) } & \multicolumn{4}{|c|}{ OLR (LW) } & \multicolumn{4}{|c|}{ RSR (SW) } \\
\hline & SEVIRI & CERES & $r$ & Slope & Std. dev. & Bias & $r$ & Slope & Std. dev. & bias \\
\hline $02 / 02$ & $02: 15$ & $02: 07-02: 23$ & 0.95 & 1.02 & 7.14 & -5.21 & - & - & - & - \\
\hline $24 / 03$ & 08:00 & 08:00-08:13 & 0.97 & 0.99 & 7.75 & 1.80 & 0.96 & 1.07 & 35.44 & -15.99 \\
\hline 08/04 & $07: 30$ & $07: 14-07: 29$ & 0.96 & 0.99 & 7.59 & 2.18 & 0.96 & 1.08 & 33.83 & -16.81 \\
\hline $14 / 06$ & $11: 15$ & 11:00-11:19 & 0.97 & 1.00 & 8.88 & 1.10 & 0.97 & 1.13 & 45.67 & -30.88 \\
\hline $02 / 09$ & $12: 45$ & $12: 38-12: 57$ & 0.98 & 1.02 & 7.00 & -5.95 & 0.98 & 1.06 & 34.74 & -7.48 \\
\hline $15 / 10$ & $18: 45$ & $18: 35-18: 59$ & 0.94 & 1.00 & 6.71 & 0.45 & - & - & - & - \\
\hline $10 / 11$ & $21: 00$ & $20: 50-20: 59$ & 0.92 & 0.99 & 14.40 & 0.82 & - & - & - & - \\
\hline $22 / 12$ & $23: 30$ & $23: 14-23: 29$ & 0.90 & 1.01 & 13.05 & -2.75 & - & - & - & - \\
\hline
\end{tabular}

by studying the relative differences between CERES and MSG/SEVIRI irradiances as a function of a number of parameters likely to influence the calculations, such as:

- solar zenith angle, to discard instrument artifacts or the influence of the diurnal variability of clouds,

- satellite (MSG) zenith angle, that could be a source of error in the areas observed under extreme viewing geometry,

- time delay between TERRA and MSG overpasses, that may cause artifacts due to the movement of clouds,

- latitude/longitude, that may cause misplacement of clouds when mapping, and

- cloud cover.

These analyses revealed hardly any dependence on any of the parameters studied. A slightly higher relative difference was found over bright areas such as high optically thick clouds or the desert. This could already be anticipated in
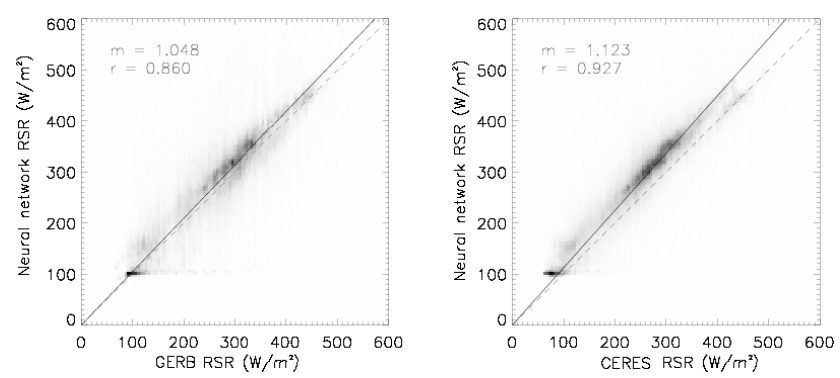

Fig. 10. Comparison between GERB and CERES observations of the RSR and the RRUMS retrieval shown in Fig. 9. The solid line corresponds to the linear fit $y=m x$ and the dashed line shows the $1: 1$ ideal behaviour, for reference. Date: 1 January 2007, 10:00 UTC

Fig. 9, where some areas of the desert and some of the cloud structures showed higher SW irradiances than in the CERES or GERB measurements (some of the areas that appear green in GERB or CERES, appear red in the RRUMS neural network scene). Figure 11, corresponding to the same area, 
Table 4. Comparison between SEVIRI-based RRUMS retrieval and GERB measurements. Bias and standard deviation in $\mathrm{W} \mathrm{m}^{-2}$.

\begin{tabular}{|c|c|c|c|c|c|c|c|c|c|}
\hline \multicolumn{2}{|c|}{ Overpass time (UTC) } & \multicolumn{4}{|c|}{ OLR (LW) } & \multicolumn{4}{|c|}{ RSR (SW) } \\
\hline SEVIRI & GERB & $r$ & Slope & Std. dev. & Bias & $r$ & Slope & Std. dev. & Bias \\
\hline 18/05/06 08:30 & $08: 35$ & 0.98 & 1.01 & 9.21 & -0.99 & - & - & - & - \\
\hline 18/05/06 11:30 & $11: 27$ & 0.98 & 1.00 & 10.54 & -3.44 & 0.97 & 1.03 & 35.30 & -11.90 \\
\hline 20/05/06 03:00 & 03:00 & 0.97 & 1.01 & 8.92 & -0.18 & - & - & - & - \\
\hline 22/05/06 00:15 & $00: 14$ & 0.96 & 1.01 & 7.64 & 0.28 & - & - & - & - \\
\hline 25/05/06 15:00 & 15:01 & 0.97 & 1.01 & 11.23 & -2.19 & 0.96 & 1.01 & 30.78 & -1.69 \\
\hline 29/05/06 14:15 & $14: 17$ & 0.97 & 1.01 & 9.51 & -0.21 & 0.96 & 1.03 & 37.41 & -9.29 \\
\hline 01/06/06 06:30 & $06: 25$ & 0.98 & 1.01 & 6.46 & -0.24 & - & - & - & - \\
\hline 01/06/06 12:45 & $12: 41$ & 0.97 & 1.00 & 9.35 & -1.37 & 0.95 & 1.04 & 45.08 & -0.52 \\
\hline 01/06/06 22:00 & $21: 58$ & 0.97 & 1.01 & 7.15 & 1.30 & - & - & - & - \\
\hline 03/06/06 10:00 & 09:54 & 0.97 & 1.00 & 8.35 & -2.23 & 0.96 & 1.05 & 38.47 & -0.30 \\
\hline 10/06/06 22:00 & 22:02 & 0.97 & 1.01 & 7.81 & 1.57 & - & - & - & - \\
\hline 12/06/06 07:30 & $07: 24$ & 0.98 & 1.01 & 7.78 & -1.48 & 0.95 & 1.04 & 31.40 & -6.16 \\
\hline
\end{tabular}
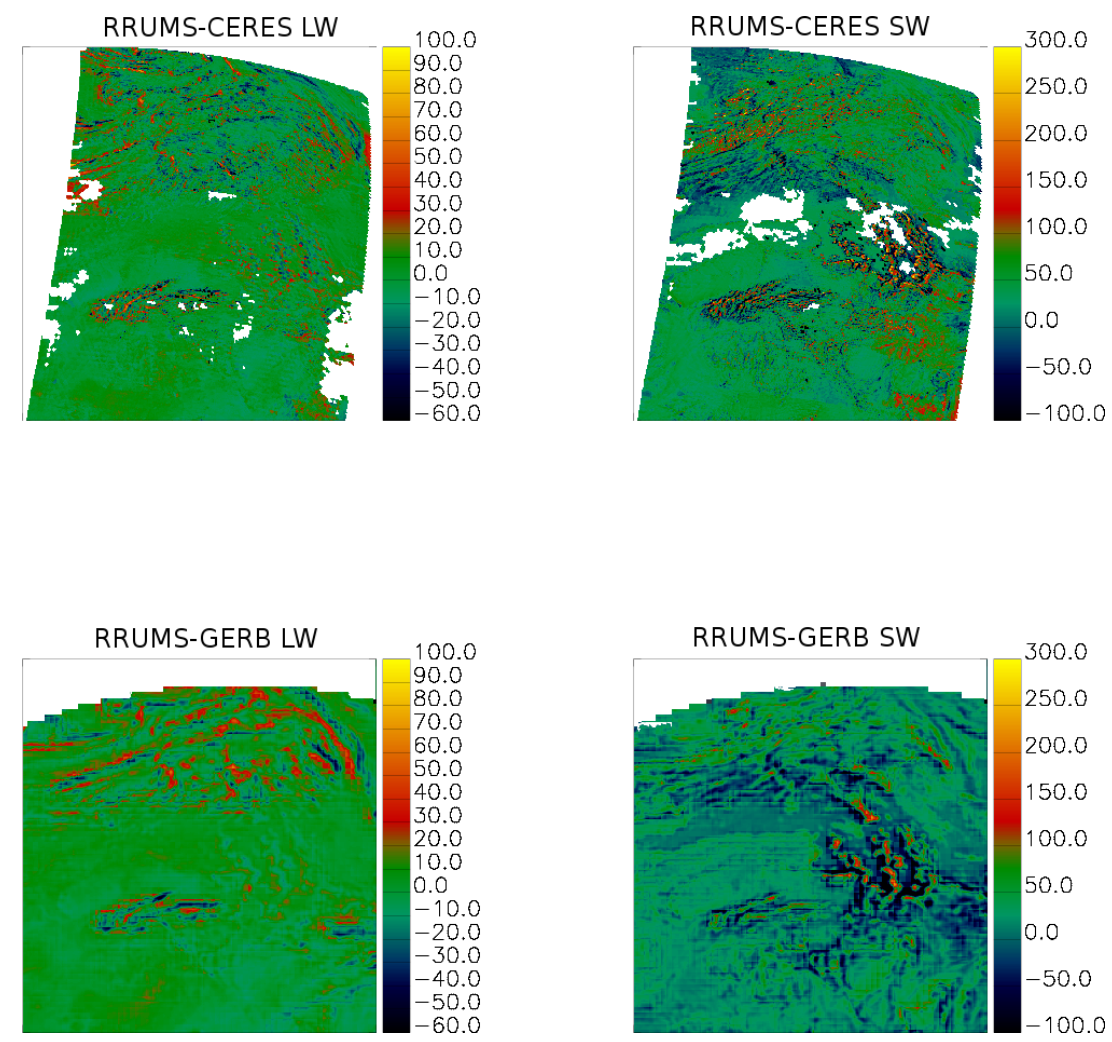

Fig. 11. Absolute differences in $\mathrm{W} \mathrm{m}^{-2}$ between the SEVIRI-based RRUMS methods and the CERES (top) and GERB (bottom) measurements in both LW (left) and SW (right). The higher differences are found around cloudy areas. Date: 1 January 2007, 10:00 UTC.

shows the absolute differences between RRUMS-retrieval and CERES (or GERB). A simple comparison with the false colour composite (Fig. 7) shows that the higher relative differences are found around cloudy areas in both LW and SW retrievals, especially along the cloud boundaries.

The slight dependence of the relative difference on cloud cover between the SEVIRI-based RRUMS method and CERES is also observed in Fig. 12. It is possibly due to a combination of the ADM selection, the cloud inhomogeneity, and three-dimensional radiative transfer effects. Also, misplacements of cloud structures can lead to additional errors. It must be noted that, although slightly larger errors were found around cloudy areas, this does not necessarily mean that the RRUMS irradiance computation over such areas is wrong. Even though the mapping in the comparison between RRUMS and CERES has been carefully performed, it could 

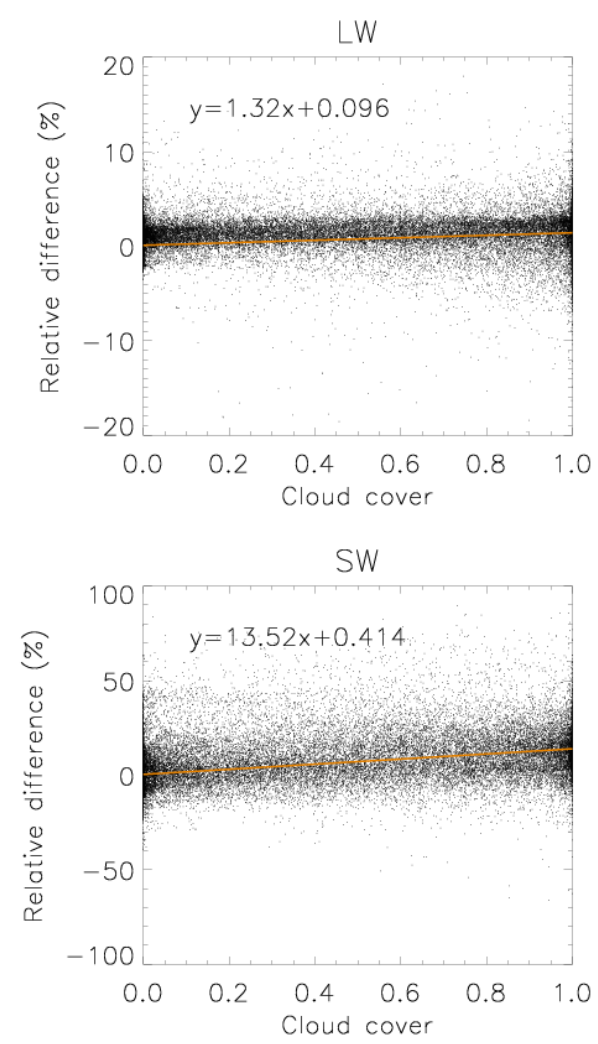

Fig. 12. Dependence of the CERES and RRUMS relative difference on cloud cover.

lead to a misplacement of cloudy structures, particularly for high clouds and/or large viewing zenith angles. Finally, an additional contribution to the increasing errors in these areas lies in the fact that sensors do not observe the exactly same scene due to small time differences: clouds are rapidly changing.

The validation with GERB (see example in Fig. 11 and further comparisons in Table 4) shows also a very good agreement. Missing SW irradiance data in the table correspond again to nighttime scenes. The standard deviation (RRUMS - GERB) for OLR averaged over all cases was $8 \mathrm{~W} \mathrm{~m}^{-2}$. The average standard deviation amounted up to $45 \mathrm{~W} \mathrm{~m}^{-2}$ for daytime RSR.

Both validations show that the RRUMS OLR and RSR retrieval algorithms for SEVIRI described here provide accurate results for our purpose. The OLR agreed better than $1 \%$ with CERES on average over all test cases. The SW irradiance was higher than CERES or GERB by 5 to $10 \%$. The deviation has been shown to be independent of solar and satellite zenith angles, and to be only slightly dependent on cloud cover. Therefore, the results are suitable for determining small scale variability and diurnal variations, thanks to the high temporal and spatial resolution of the SEVIRI instrument. A further advantage of RRUMS is the fast processing time of the algorithm. Additionally, RRUMS does not require a full scene classification or ADMs for the irradiance retrievals.

\section{Conclusions}

The RRUMS algorithms described here retrieve OLR and RSR from MSG/SEVIRI. In the longwave range, it has been shown that the developed linear combination of the thermal infrared channels is a reliable method to calculate the OLR. For the SW range a neural network has been described. A simpler approach (linear fit) was also developed but, when compared to CERES and GERB, the uncertainty was slightly higher than that of the neural network, and it has therefore been omitted here.

The retrievals have been compared to measurements from the CERES and GERB broadband radiometers. The validation of RRUMS with the CERES and GERB irradiance data showed excellent agreement in the OLR and a systematic over-estimation in the SW. As a result of the validation it can be stated that the agreement in OLR with CERES is $1 \%$ and the agreement with CERES or GERB in RSR is 5 to $10 \%$ (in the worst cases, under high viewing angles). The accuracy of the CERES instrument for OLR and RSR irradiance retrievals is $1 \%$ and $0.5 \%$, respectively (Wielicki et al., 1998). The accuracy of GERB does not meet the initial mission target requirements and lies in the range of $1-2 \%$ (OLR) and 7-8 \% (RSR) (Russell et al., 2006). It must be mentioned that any calibration uncertainty of the SEVIRI instrument would directly affect the derived irradiances. The thermal algorithm is linear, and a calibration uncertainty of $1 \%$ translates to an uncertainty of $1 \%$ in the products. To test the effect of a $1 \%$ uncertainty on the RSR, the neural network has been applied using reflectivities increased by $1 \%$ which also translated to an increase of about $1 \%$ in the irradiance. In an intercalibration study on the SEVIRI solar channels with the corresponding MODIS channels (Meirink et al., 2013), the SEVIRI operational calibration was found to be stable during the years 2004 to 2009 , but off by $-8,-6$, and $+3.5 \%$ for channels VIS006, VIS008 and IR_016, respectively.

Thus, the shortwave and the longwave MSG/SEVIRIbased irradiance retrieval algorithms (RRUMS) presented in this paper can be used as a tool to retrieve irradiances taking advantage of the temporal and spatial resolution of the SEVIRI sensor. The irradiances are computed on the SEVIRI pixel grid, taking advantage of the SEVIRI spatial and temporal resolution. Moreover, the computation is fully automatic and very fast. We want to point out again that our algorithm is not meant to provide accurate absolute results of the Earth radiation budget, where more accurate instruments like CERES are available. Rather, this method is specifically developed for determining the radiative effects of small scale features such as cirrus clouds and aircraft contrails, where the spatial and temporal resolutions of CERES and GERB are insufficient. A further advantage is that the only satellite 
information RRUMS requires are the SEVIRI data. RRUMS is an excellent counterpart to the radiometrically more accurate CERES instrument when the focus is on the smaller scales.

\section{Supplementary material related to this article is available online at http://www.atmos-meas-tech.net/6/ 2627/2013/amt-6-2627-2013-supplement.zip.}

Acknowledgements. This research was supported by the EU FP6 QUANTIFY project and by the EU FP7 REACT4C project. The authors would like to thank Ulrich Schumann, Klaus Gierens and Luca Bugliaro for their very valuable comments and suggestions.

We dedicate this paper to the memory of our friend and colleague Hermann Mannstein, who, sadly, passed away in January. His long experience in the field of cloud remote sensing and his tiredless enthusiasm constitute a great personal and professional loss.

The service charges for this open access publication have been covered by a Research Centre of the Helmholtz Association.

Edited by: A. Macke

\section{References}

Chevallier, F., Cheruy, F., Scott, N., and Chedin, A.: A neural network approach for a fast and accurate computation of a longwave radiative budget, J. Appl. Meteorol., 37, 1385-1397, 1998.

Clerbaux, N., Dewitte, S., Gonzalez, L., Bertrand, C., Nicula, B., and Ipe, A.: Outgoing longwave flux estimation: improvement of angular modelling using spectral information, Remote Sens. Environ., 85, 389-395, 2003.

Clerbaux, N., Dewitte, S., Bertrand, C., Caprion, D., De Paepe, B., Gonzalez, L., Ipe, A., and Russell, J.: Unfiltering of the Geostationary Earth Radiation Budget (GERB) data. Part II: Longwave radiation, J. Atmos. Ocean. Technol., 25, 1106-1117, 2008a.

Clerbaux, N., Dewitte, S., Bertrand, C., Caprion, D., De Paepe, B., Gonzalez, L., Ipe, A., Russell, J., and Brindley, H.: Unfiltering of the Geostationary Earth Radiation Budget (GERB) Data. Part I: Shortwave Radiation, J. Atmos. Ocean. Technol., 25, 10871105, 2008b.

Cox, C. and Munk, W.: Statistics of the sea surface derived from sun glitter, J. Marine Res., 13, 198-227, 1954.

Davis, A., Marshak, A., Cahalan, R., and Wiscombe, W.: The Landsat scale break in stratocumulus as a three-dimensional radiative transfer effect: Implications for cloud remote sensing, J. Atmos. Sci., 54, 241-260, 1997.

Diner, D., Asner, G., Davies, R., Knyazikhin, Y., Muller, J.-P., Nolin, A., Pinty, B., Schaaf, C., and Stroeve, J.: New directions in Earth observing: Scientific applications of multiangle remote sensing, B. Am. Meteorol. Soc., 80, 2209-2228, 1999.

EUMETSAT: Outgoing Longwave Radiation Factsheet, EUM/OPS/DOC/09/5176 Edn., 2010.
Ewald, F., Bugliaro, L., Mannstein, H., and Mayer, B.: An improved cirrus detection algorithm MeCiDA2 for SEVIRI and its evaluation with MODIS, Atmos. Meas. Tech., 6, 309-322, doi:10.5194/amt-6-309-2013, 2013.

Harries, J., Russell, J., Hanafin, J., Brindley, H., Futyan, J., Rufus, J., Kellock, S., Matthews, G., Wrigley, R., Last, A., Mueller, J., Mossavati, R., Ashmall, J., Sawyer, E., Parker, D., Caldwell, M., Allan, P., Smith, A., Bates, M., Coan, B., Stewart, B., Lepine, D., Cornwall, L., Corney, D., Ricketts, M., Drummond, D., Smart, D., Cutler, R., Dewitte, S., Clerbaux, N., Gonzalez, L., Ipe, A., Bertrand, C., Joukoff, A., Crommelynck, D., Nelms, N., Llewellyn-Jones, D., Butcher, G., Smith, G., Szewczyk, Z., Mlynczak, P., Slingo, A. R. P. A., and Ringer, M.: The Geostationary Earth Radiation Budget Project, B. Am. Meteorol. Soc., 86, 945-960, 2005.

Key, J., Yang, P., Baum, B., and Nasiri, S.: Parameterization of shortwave ice cloud optical properties for various particle habits, J. Geophys. Res., 107, AAC7.1-AAC7.10, doi:10.1029/2001JD000742, 2002.

Krebs, W., Mannstein, H., Bugliaro, L., and Mayer, B.: Technical note: A new day- and night-time Meteosat Second Generation Cirrus Detection Algorithm MeCiDA, Atmos. Chem. Phys., 7, 6145-6159, doi:10.5194/acp-7-6145-2007, 2007.

Loeb, N., Parol, F., Buriez, J.-C., and Vanbauce, C.: Top-ofatmosphere albedo estimation from angular distribution models using scene identification from satellite cloud property retrievals, J. Climate, 13, 1269-1285, 2000.

Loeb, N., Manalo-Smith, N., Kato, S., Miller, W., Gupta, S., Minnis, P., and Wielicki, B.: Angular distribution models for topof-atmosphere radiative flux estimation from the Clouds and the Earth's Radiant Energy System Instrument on the Tropical Rainfall Measurement Mission satellite: Part I: Methodology, J. Appl. Meteorol., 42, 240-265, 2003.

Loeb, N., Kato, S., Loukachine, K., and Manalo-Smith, N.: Angular Distribution Models for Top-of-Atmosphere Radiative Flux Estimation from the Clouds and the Earth's Radiant Energy System Instrument on the Terra Satellite. Part I: Methodology, J. Atmos. Ocean. Technol., 22, 338-351, 2005.

Loeb, N., Kato, S., Loukachine, K., Manalo-Smith, N., and Doelling, D.: Angular Distribution Models for Top-ofAtmosphere Radiative Flux Estimation from the Clouds and the Earth's Radiant Energy System Instrument on the Terra Satellite. Part II: Validation, J. Atmos. Ocean. Technol., 24, 564-584, 2007.

Loeb, N. G., Wielicki, B. A., Doelling, D. R., Smith, G. L., Keyes, D. F., Kato, S., Manalo-Smith, N., and Wong, T.: Toward optimal closure of the earth's top-of-atmosphere radiation budget, J. Climate, 22, 748-766, doi:10.1175/2008JCLI2637.1, 2009.

Mayer, B. and Kylling, A.: Technical note: The libRadtran software package for radiative transfer calculations - description and examples of use, Atmos. Chem. Phys., 5, 1855-1877, doi:10.5194/acp-5-1855-2005, 2005.

Mayer, B., Seckmeyer, G., and Kylling, A.: Systematic long-term comparison of spectral UV measurements and UVSPEC modeling results, J. Geophys. Res., 102, 8755-8767, 1997.

Meirink, J. F., Roebeling, R. A., and Stammes, P.: Inter-calibration of polar imager solar channels using SEVIRI, Atmos. Meas. Tech. Discuss., 6, 3215-3247, doi:10.5194/amtd-6-3215-2013, 2013. 
Nakajima, T. and Tanaka, M.: Effect of wind-generated waves on the transfer of solar radiation in the atmosphere-ocean system, J. Quant. Spectrosc. Ra., 29, 521-537, 1983.

Pierluissi, J. and Peng, G.-S.: New molecular transmission band models for LOWTRAN, Opt. Eng., 24, 541-547, 1985.

Rahman, H., Verstraete, M., and Pinty, B.: Coupled surfaceatmosphere reflectance (CSAR) model. 2. Semiempirical surface model usable with NOAA advanced very high resolution radiometer data, J. Geophys. Res., 98, 20791-20801, 1993.

Ricchiazzi, P. and Gautier, C.: Investigation of the effect of surface heterogeneity and topography on the radiation environment of Palmer Station, Antarctica, with a hybrid 3-D radiative transfer model, J. Geophys. Res., 103, 6161-6178, 1998.

Ricchiazzi, P., Yang, S., Gautier, C., and Sowle, D.: SBDART: A research and Teaching software tool for plane-parallel radiative transfer in the Earth's atmosphere, B. Am. Meteorol. Soc., 79, 2101-2114, 1998.

Russell, J. E., Dewitte, S., and Harries, J. E.: Quality Summary: GERB L2 ARG, 3 scan average Edition 1 product, GERB project team, 2006.

Schmetz, J., Pili, P., Tjemkes, S., Just, D., Kerkmann, J., Rota, S., and Ratier, A.: An introduction to Meteosat Second Generation (MSG), B. Am. Meteorol. Soc., 83, 977-992, 2002.

Sobrino, J. and Cuecas, J.: Angular variation of thermal infrared emissivity for some natural surfaces from experimental measurements, Appl. Optics, 38, 3931-3936, 1999.

Stamnes, K., Tsay, S., Wiscombe, W., and Jayaweera, K.: A numerically stable algorithm for discrete-ordinate-method radiative transfer in multiple scattering and emitting layered media, Appl. Optics, 27, 2502-2509, 1988.

Sun, W., Loeb, N. G., Davies, R., Loukachine, K., and Miller, W. F.: Comparison of MISR and CERES top-of-atmosphere albedo, Geophys. Res. Lett., 33, L23810, doi:10.1029/2006GL027958, 2006.
Van Weele, M., Martin, T., Blumthaler, M., Brogniez, C., den Outer, P., Engelsen, O., Lenoble, J., Pfister, G., Ruggaber, A., Walravens, B., Weihs, P., Dieter, H., Gardiner, B., Gillotay, D., Kylling, A., Mayer, B., Seckmeyer, G., and Wauben, W.: From model intercomparisons towards benchmark UV spectra for six real atmospheric cases, J. Geophys. Res., 105, 4915-4925, 2000.

Varnai, T. and Marshak, A.: Statistical analysis of the uncertainties in cloud optical depth retrievals caused by three-dimensional radiative effects, J. Atmos. Sci., 58, 1540-1548, 2001.

Vazquez-Navarro, M., Mannstein, H., and Mayer, B.: An automatic contrail tracking algorithm, Atmos. Meas. Tech., 3, 1089-1101, doi:10.5194/amt-3-1089-2010, 2010.

Wielicki, B., Barkstrom, B., Harrison, E., Lee III, R., Smith, G., and Cooper, J.: Clouds and the Earth's Radiant Energy System (CERES): An Earth Observing System Experiment, B. Am. Meteorol. Soc., 77, 853-868, 1996.

Wielicki, B. A., Barkstrom, B. R., Baum, B. A., Charlock, T. P., Green, R. N., Kratz, D. P., Robert B. Lee, I., Minnis, P., Smith, G. L., Wong, T., Young, D. F., Cess, R. D., James A. Coakley, J., Crommelynck, D. A. H., Donner, L., Kandel, R., King, M. D., Miller, A. J., Ramanathan, V., Randall, D. A., Stowe, L. L., and Welch, R. M.: Clouds and the Earth's Radiant Energy System (CERES): Algorithm Overview, IEEE T. Geosci. Remote, 36, 1127-1141, 1998.

Yang, P., Wei, H., Huang, H.-L., Baum, B., Hu, Y., Kattawar, G., Mishchenko, M., and Fu, Q.: Scattering and absorption property database for nonspherical ice particles in the near- through farinfrared spectral region, Appl. Optics, 44, 5512-5523, 2005.

Zinner, T. and Mayer, B.: Remote sensing of stratocumulus clouds: Uncertainty and biases due to inhomogeneity, J. Geophys. Res., 111, D14209, doi:10.1029/2005JD006955, 2006. 